Article

\title{
Exploring Basic Components Effect on the Catalytic Efficiency of Chevron-Phillips Catalyst in Ethylene Trimerization
}

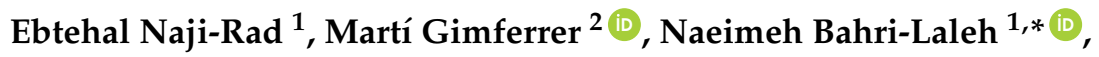 \\ Mehdi Nekoomanesh-Haghighi ${ }^{1}$, Roghieh Jamjah ${ }^{1}$ and Albert Poater ${ }^{2, *}$ (D) \\ 1 Polymerization Engineering Department, Iran Polymer and Petrochemical Institute (IPPI), \\ P.O. Box 14965/115 Tehran, Iran; enajirad@gmail.com(E.N.-R.); m.nekoomanesh@ippi.ac.ir (M.N.-H.); \\ r.jamjah@ippi.ac.ir (R.J.) \\ 2 Departament de Química, Universitat de Girona, Institut de Química Computacional i Catàlisi, \\ Campus de Montilivi sn, 17003 Girona, Catalonia, Spain; mgimferrer18@gmail.com \\ * Correspondence: n.bahri@ippi.ac.ir (N.B.-L.); albert.poater@udg.edu (A.P.); \\ Tel.: +98-2148662479 (N.B.-L.); +34-972418358 (A.P.)
}

Received: 26 April 2018; Accepted: 18 May 2018; Published: 24 May 2018

\begin{abstract}
In the present work, the effect of basic components on the energy pathway of ethylene oligomerization using the landmark Chevron-Phillips catalyst has been explored in detail, using density functional theory (DFT). Studied factors were chosen considering the main components of the Chevron-Phillips catalyst, i.e., ligand, cocatalyst, and halocarbon compounds, comprising (i) the type of alkyl substituents in pyrrole ligand, i.e., methyl, iso-propyl, tert-butyl, and phenyl, as well as the simple hydrogen and the electron withdrawing fluoro and trifluoromethyl; (ii) the number of $\mathrm{Cl}$ atoms in $\mathrm{Al}$ compounds (as $\mathrm{AlMe}_{2} \mathrm{Cl}, \mathrm{AlMeCl}_{2}$ and $\mathrm{AlCl}_{3}$ ), which indicate the halocarbon level, and (iii) cocatalyst type, i.e., alkylboron, alkylaluminium, or alkylgallium. Besides the main ingredients, the solvent effect (using toluene or methylcyclohexane) on the oligomerization pathway was also explored. In this regard, the full catalytic cycles for the main product (1-hexene) formation, as well as side reactions, i.e., 1-butene release and chromacyclononane formation, were calculated on the basis of the metallacycle-based mechanism. According to the obtained results, a modification on the Chevron-Phillips catalyst system, which demonstrates higher 1-hexene selectivity and activity, is suggested.
\end{abstract}

Keywords: Chevron-Phillips; chromium; trimerization; polymerization; reaction pathway

\section{Introduction}

Linear $\alpha$-olefins are valuable products obtained from the petrochemical industry. They are commonly used in polyethylene products, and as plasticizer alcohols, synthetic lubricants, or surfactants between other applications. Among all $\alpha$-olefin monomers, 1-hexene has attracted considerable attention, since superior copolymer properties are achieved using it as a comonomer, as compared to the characteristics of 1-butene/ethylene copolymers [1]. Although 1-hexene is currently mainly produced via full-range processes, catalytic selective trimerization of ethylene to 1-hexene is an area of intense research activity [2-4]. Even though many companies are interested in the topic, only the Chevron-Phillips trimerization process has been commercialized so far [5]. The main reasons for choosing this system over other trimerization systems, such as Cr/PNP or Cr/SNS, are: (1) high activity and selectivity for 1-hexene production; (2) its cocatalyst, i.e., triethylaluminium (TEAL), is much cheaper than the methylaluminoxane (MAO); (3) the synthesis of mono-dentate ligands is 
much easier and cheaper than the tri-dentate ones used in the Chevron-Phillips catalyst and in Cr/PNP and Cr/SNS systems, respectively [6,7].

The Chevron-Phillips catalyst mainly consists of a Cr-containing precursor, a pyrrole ligand, an Al-alkyl cocatalyst, and a promoter [8]. Due to the importance of the Chevron-Phillips ethylene trimerization catalyst, various experimental and theoretical studies have been conducted in recent years which have allowed us to establish some widely accepted ideas $[9,10]$. For example, there is a compromise that the catalytic cycle is accomplished via the formation of a metallacycle pathway in which the chromium centre operates via a redox $\mathrm{Cr}(\mathrm{I} / \mathrm{III})$ metallacyclic mechanism [11]. In fact, theoretical studies of the activation energies for different stages of the trimerization process have revealed that the model containing $\mathrm{Cr}$ (I/III) redox has lower energy levels than the $\mathrm{Cr}$ (II/IV) species, due to greater stability of the oxidation state in the $\mathrm{Cr}$ (I/III) system [12]. This finding was further supported by the experimental results from an electron paramagnetic resonance (EPR) investigation on the same catalytic system [13].

Due to massive investigations on Chevron-Phillips catalytic system, the following precursors presented the highest activity: chromium(III) 2-ethylhexanoate $\left(\mathrm{Cr}(\mathrm{EH})_{3}\right)$ as catalyst, 2,5-dimethylpyrrole (2,5-DMP) as ligand, $\mathrm{AlEt}_{3}$ as cocatalyst, and a modifier [6]. Studies revealed that halocarbons containing two or more $\mathrm{Cl}$ atoms are good candidates in trimerization processes. However, their exact role as modifiers is still in debate.

Based on the aforementioned catalytic precursors, the active site model (shown in Scheme 1) is considered as an active catalyst in the trimerization process [14,15]. This catalyst mainly consists of a pyrrole ring coordinated to the $\mathrm{Cr}$ center, together with a pendant $\mathrm{R}_{2} \mathrm{AlCl}$ group $\sigma$-bonded to the pyrrole ligand, via Al-N linkage, and to the $\mathrm{Cr}$ metal, via $\mathrm{Cr}-\mathrm{Cl}$ linkage. It is supposed that the $\mathrm{R}_{2} \mathrm{AlCl}$ formation occurs via the simple reaction of TEAL with halocarbon promoters.

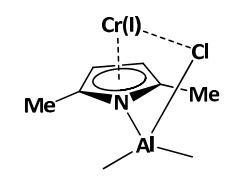

Scheme 1. Model catalyst A.

Despite the proven performance of such a system, the development of improved catalysts is one of the chief areas of research in this field. For this reason, in this work a systematic study was done to shed light on: (i) the effects of alkyl substituents on ligand structures; (ii) the number of $\mathrm{Cl}$ atoms in the $\mathrm{Al}$ compound; (iii) the revenue of $\mathrm{Al}$ substitution for $\mathrm{B}$ or $\mathrm{Ga}$, and (iv) the solvent-type effect in the energy profile of the reaction pathway (See Scheme 2). Consequently, we have suggested modifications to the Chevron-Phillips system.

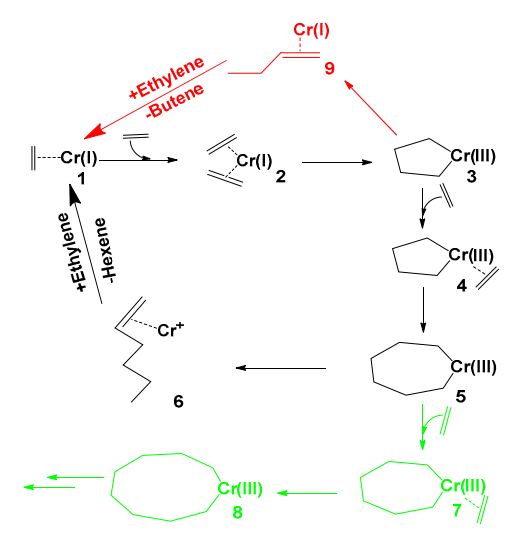

Scheme 2. Ethylene oligomerization catalytic cycle (the ligands on the chromium center are omitted for the sake of clarity). 


\section{Results and Discussion}

The mechanism of ethylene oligomerization using the Chevron-Phillips catalyst is illustrated in Scheme 2. In this procedure, the reaction starts with the coordination of the first and second ethylene molecules into the empty site of chromium (I) (steps 1 and 2), and proceeds to the first 5-membered metallacycle formation (3), via oxidative addition through the transition state TS-2-3. In this step, the catalyst can undergo two different transformations: (i) the main reaction, which consists of the coordination and insertion of a third ethylene molecule (4), subsequently leading to the formation of the 7-membered metallacycle (5); (ii) the side reaction, in which the elimination of 1-butene (9) occurs (dimerization, red diagram in Scheme 2). The main product, 1-hexene, is formed via the opening of the ring (5), and the reductive elimination of 1-hexene from the rather unstable chroma cycloheptane (trimerization, black diagram in Scheme 2). Another side reaction can also occur in this pathway, based firstly on the coordination of a fourth ethylene molecule, and then on its insertion into the 7-membered chromic cycloheptane (5), leading to the 9-membered metallacycle 8 (ethylene tetramerization, green diagram in Scheme 2). Furthermore, a two-step process that leads to 3 from 2 was also attempted, bearing a first $\mathrm{H}$ transfer; however, it was omitted from the analysis since kinetically it was found to be much less efficient.

For the parent model system A, the energy profile calculated in Figure 1 is very similar to that calculated earlier by Liu and coworkers [12]. The rate for determining step size (rds) turned out to be the transition state leading to the formation of the 7 -membered metallacycle $\mathbf{5 A}$, with an upper barrier placed at $24.9 \mathrm{kcal} / \mathrm{mol}$ over intermediate $\mathbf{3 A}$, which is slightly less efficient compared to the previous results of Liu [12]. The alternative, undesired reactions that lead to $\mathbf{8 A}$ and $\mathbf{9 A}$, were found to be less kinetically efficient, by 8.8 and $1.6 \mathrm{kcal} / \mathrm{mol}$, respectively. In order to unveil the complexity of the described reaction pathway, ten other model catalysts were tested in the following sections.

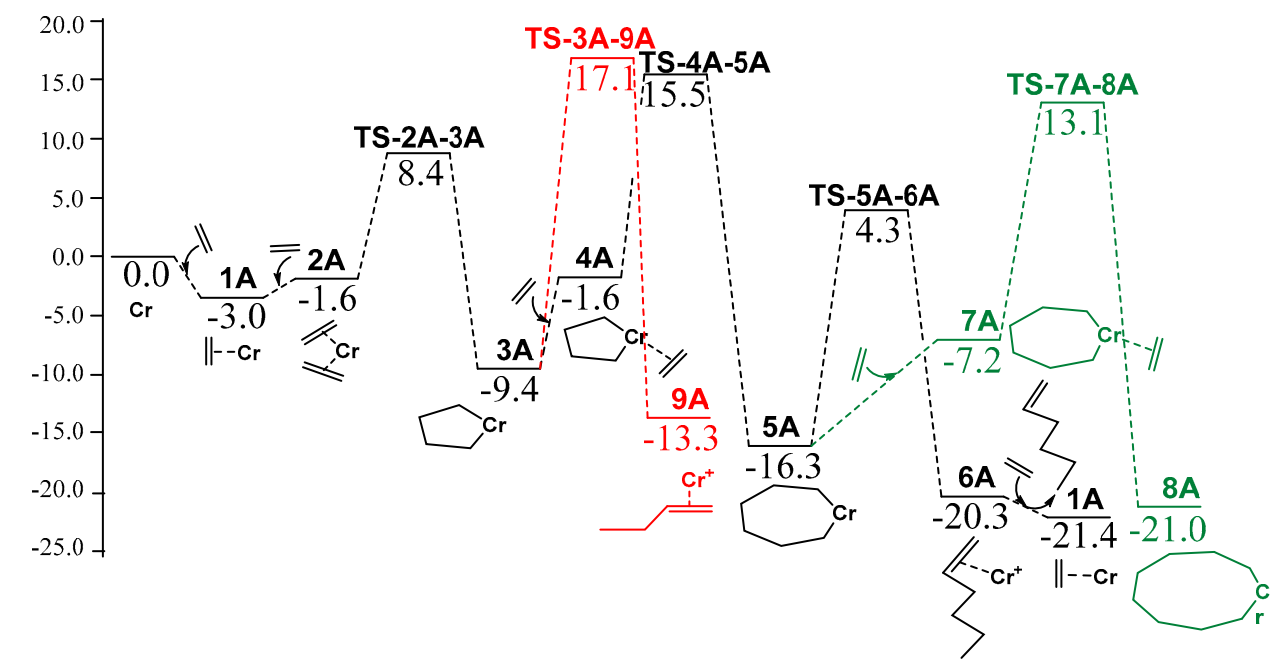

Figure 1. Calculated reaction profile for model A catalyst (free energies in $\mathrm{kcal} / \mathrm{mol}$ ). Black and red lines illustrate Gibbs free energies in solvent of ethylene tri- and dimerization, respectively, in green the alternative formation of the 9-membered ring.

\subsection{Effect of Alkyl Substituents on the Pyrrole Ligand}

As a first step, the effect of the steric hindrance from dialkylpyrole-type ligands on the energetic profile of the reaction pathway was elucidated. For this purpose, the three different molecular models, B, C and D (Scheme 3), corresponding to dihydride-, diisopropyl-, and ditertbutyl-pyrrole, respectively, were employed and compared to the dimethyl-pyrrole (model A). The selected models differ mainly in the alkyl group of the pyrrole ligand. First, the steric hindrance of the catalysts was analyzed by the SambVca2 Web application [16]. This application extracts the topographic maps (Figure 2), which are 
simple two-dimensional isocontours representing the interaction surface, by evaluating the percent buried volume (\%VBur) in the single quadrants around the metal center. \%VBur values were obtained by analyzing the steric bulk of the pyrrole ligands in the DFT optimized structures of the A, B, C and D model complexes. \%VBur values of $63.3,64.6,66.8$ and $69.1 \%$ in $\mathbf{B}, \mathbf{A}, \mathbf{C}$ and $\mathbf{D}$, respectively, highlighted an obvious difference in steric bulkiness between these four complexes, with A clearly less bulky than $\mathbf{C}$, and still less that $\mathbf{D}$.
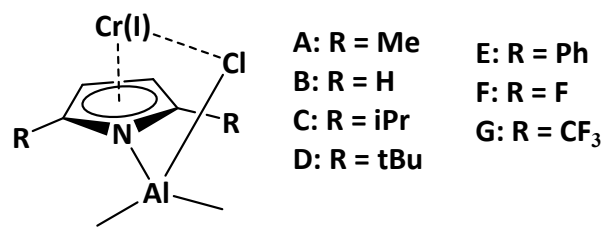

Scheme 3. Model catalysts (A-G) to study the steric and electronic effects of alkyl substituents on the pyrrole ligand.

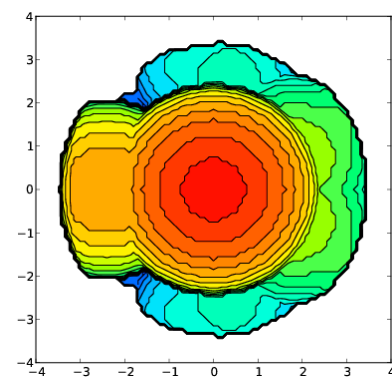

(a)

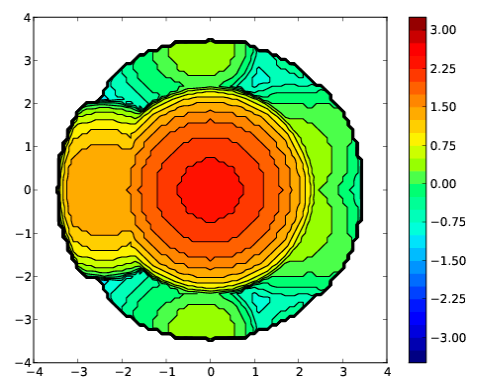

(b)

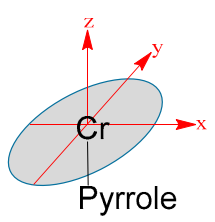

Pyrrole

Figure 2. Topographic steric maps of the pyrrole ligands (plane xy) for the optimized complexes (a) A and (b) D. The Cr atom is at the origin and the center of mass of the pyrrole is on the $\mathrm{z}$ axis. The isocontour curves of the steric maps are given in $\AA$.

The whole energy profile of the reaction pathway for ethylene oligomerization using model catalysts B, C, and D is shown in Table 1, together with the study of the electronic effect of the substituents on the pyrrole ligand, by means of model catalysts $\mathbf{E}, \mathbf{F}$, and $\mathbf{G}$, bearing phenyl, fluoro and trifluoromethyl groups, respectively.

Table 1. Relative Gibbs free energies in toluene for models $\mathbf{A}-\mathbf{G}$ of the ethylene dimerization, trimerization, and the formation of the 7- and also the 9-membered ring. All energies are in $\mathrm{kcal} / \mathrm{mol}$.

\begin{tabular}{cccccccc}
\hline Model Catalyst & A & B & C & D & E & F & G \\
\hline Active species & 0.0 & 0.0 & 0.0 & 0.0 & 0.0 & 0.0 & 0.0 \\
$\mathbf{1}$ & -3.0 & -2.0 & -3.2 & -3.6 & -0.6 & 2.1 & 2.1 \\
$\mathbf{2}$ & -1.6 & 0.0 & 2.2 & 4.6 & 7.3 & 0.4 & 5.3 \\
TS-2-3 & 8.4 & 10.4 & 9.6 & 12.1 & 18.3 & 10.4 & 13.9 \\
$\mathbf{3}$ & -9.4 & -7.7 & -9.4 & -7.8 & -6.9 & -3.8 & -3.1 \\
$\mathbf{4}$ & -1.6 & 0.2 & 3.6 & 1.2 & 2.8 & 0.8 & 8.3 \\
TS-4-5 & 15.5 & 17.3 & 17.4 & 14.1 & 20.0 & 16.9 & 9.2 \\
$\mathbf{5}$ & -16.3 & -13.9 & -15.5 & -14.2 & -13.0 & -12.7 & -11.8 \\
TS-5-6 & 4.3 & 6.7 & 5.5 & 4.6 & 10.2 & 3.6 & 6.9 \\
$\mathbf{6}$ & -20.3 & -18.8 & -19.8 & -20.2 & -17.9 & -14.6 & -14.8 \\
$\mathbf{7}$ & -7.2 & -3.2 & -5.0 & -0.2 & -2.7 & -5.9 & -1.6 \\
TS-7-8 & 13.1 & 15.0 & 13.4 & 16.8 & 15.3 & 14.0 & 18.0 \\
$\mathbf{8}$ & -21.0 & -18.9 & -19.5 & -18.3 & -17.9 & -18.2 & -16.1 \\
TS-3-9 & 17.1 & 20.8 & 18.4 & 16.1 & 26.0 & 15.7 & 16.7 \\
$\mathbf{9}$ & -13.3 & -12.5 & -13.8 & -13.4 & -11.5 & -8.1 & -7.5 \\
\hline
\end{tabular}


For a direct comparison, the energy barriers of competitive mechanisms (dimerization versus the third ethylene insertion and trimerization versus the fourth ethylene insertion) are reported in Table 2. It is worth mentioning that the formation of chromocycloheptane and chromocyclononane are the key steps to understanding 1-hexene selectivity using the mostly accepted metallacycle-based mechanism, proposed by Briggs for ethylene oligomerization $[17,18]$. The coordination of the first ethylene to the active center was slightly exergonic, with an average of $2.0-3.0 \mathrm{kcal} / \mathrm{mol}$ in all active systems, except for fluoro containing models $\mathbf{F}$ and $\mathbf{G}$. Its explanation comes from the electron-withdrawing character of the fluorides and the trifluoromethyl groups on the pyrrole ligand, which reduces the nucleophilic capacity of the chromium center [19].

Table 2. Effect of substituents and metal ( $\mathrm{B}, \mathrm{Al}, \mathrm{Ga})$ of the pyrrole ligand on the dimerization and trimerization energies, and 7- and 9-membered ring formation energies. All energies are in kcal/mol.

\begin{tabular}{|c|c|c|c|c|}
\hline Model Catalyst & $E_{T S-4-5}-E_{3}^{a}$ & $E_{T S-5-6}-E_{5}$ & $\mathrm{E}_{\mathrm{TS}-7-8}-\mathrm{E}_{5} \mathrm{~b}$ & $\mathrm{E}_{\mathrm{TS}-3-9-\mathrm{E}_{3}}$ \\
\hline A & 24.9 & 20.6 & 29.4 & 26.5 \\
\hline B & 25.0 & 20.6 & 28.9 & 28.5 \\
\hline $\mathrm{C}$ & 26.8 & 21.0 & 28.9 & 27.8 \\
\hline D & 21.9 & 18.8 & 31.0 & 23.9 \\
\hline $\mathrm{E}$ & 26.9 & 23.2 & 28.3 & 32.9 \\
\hline $\mathbf{F}$ & 20.7 & 16.3 & 26.7 & 19.5 \\
\hline G & 12.3 & 18.7 & 29.8 & 19.8 \\
\hline $\mathbf{H}$ & 21.6 & 15.8 & 25.3 & 24.7 \\
\hline I & 18.8 & 16.0 & 24.1 & 22.1 \\
\hline J & 28.7 & 22.4 & 38.7 & 25.6 \\
\hline $\mathbf{K}$ & 15.1 & 22.5 & 31.2 & 25.8 \\
\hline
\end{tabular}

${ }^{\mathrm{a}}$ Chromocycloheptane ring formation, ${ }^{\mathrm{b}}$ Chromocyclononane ring formation.

When increasing the steric hindrance from $\mathbf{A}$ to $\mathbf{D}$, the second monomer coordination became less efficient. The formation of the 5-membered chromocyclopentane was required to overcome energy barriers of 11.4 and $15.7 \mathrm{kcal} / \mathrm{mol}$ (TS-2-3) for catalysts $\mathbf{A}$ and $\mathbf{D}$, respectively. The stable chromocyclopentane 3 showed a low tendency towards $\beta-\mathrm{H}$ transfer to $\mathrm{Cr}$, i.e., the red mechanism in Scheme 2. As a result, the formation of 1-butene from intermediate 3 required conquering an effective barrier of $26.5 \mathrm{kcal} / \mathrm{mol}$ for $\mathbf{A}$, and $23.9 \mathrm{kcal} / \mathrm{mol}$ for the $\mathbf{D}$ model catalyst. Thus, this step is unaffected by the sterical hindrance of the sterically demanding tertbutyl groups of the latter system, which help to decrease the energy barrier. The insertion of the third ethylene that leads to the chromocycloheptane 5 required only $24.9,25.0,26.8,21.9$, and $26.9 \mathrm{kcal} / \mathrm{mol}$, for the series of A-E model catalysts, respectively, which means that the insertion of the third monomer somehow anticipated the chromocycloheptane opening. The poor performance of system $\mathbf{E}$ is attributed to the aromatic delocalization of the phenyls with the pyrrole ring. From an electronic point of view, fluoro containing electron-withdrawing groups reduce the kinetic cost, to reach 5 by 4.8 and $12.6 \mathrm{kcal} / \mathrm{mol}$, comparing $\mathbf{B}$ with $\mathbf{F}$, and $\mathbf{A}$ with $\mathbf{G}$, respectively.

In the following, the chromocycloheptane 5 required energy barriers of 20.6, 20.6, 21.0, 18.8, and $23.2 \mathrm{kcal} / \mathrm{mol}$ (TS-5-6) in A-E model catalysts, respectively, to release 1-hexene product. These values are at least $5 \mathrm{kcal} / \mathrm{mol}$ lower in energy than the barrier defined by the previous TS-4-5. However, for the occurrence of the second side reaction, i.e., insertion of a forth ethylene moiety into 5 , a barrier at least $5.1 \mathrm{kcal} / \mathrm{mol}$ higher in energy (TS-7-8) must be overcome. This fact makes the latter side reaction impractical. The lowest preference for the formation of 9-membered metallacycle 8 is hold by system $\mathbf{D}$, for which this process is kinetically inefficient by $12.2 \mathrm{kcal} / \mathrm{mol}$. It was deduced from reported energy results that by moving from a dimethyl- to a diisoproply- and ditertbutyl-pyrrole ligand, the selectivity toward 1-hexene formation increased. This was in line with experimental results for similar catalysts. $[6,20,21]$. The fluorinated systems $\mathbf{F}$ and $\mathbf{G}$, still computational model catalysts, increase the preference for the generation of 1-hexene, with a lower kinetic cost for TS-5-6 of 2.1 and $2.3 \mathrm{kcal} / \mathrm{mol}$, respectively. For system $\mathbf{F}$, there is the issue that the energy barrier of $19.5 \mathrm{kcal} / \mathrm{mol}$ for 
TS-3-9 that consists of the 1-butene formation is $1.2 \mathrm{kcal} / \mathrm{mol}$ lower than TS-4-5, which corresponds to the formation of the 7-membered metallacycle. Even though results for model $\mathrm{G}$ are more promising than for the catalysts A-F series, system $\mathbf{G}$ still has some structural issues. Actually, the transition state TS-4-5 was located with the five-membered ring ligand which was completely dissociated from the chromium (see Figure 3), which leads to the decomposition of the catalytic center afterwards, behaving potentially as a nanoparticle which is partially stabilized by the chloride atom of the $\mathrm{Al}(\mathrm{Me})_{2} \mathrm{Cl}$ moiety. The electron withdrawing character of the trifluoromethyl group is thus clearly competitive with the chromium affinity for the electron density of the five-membered ring.

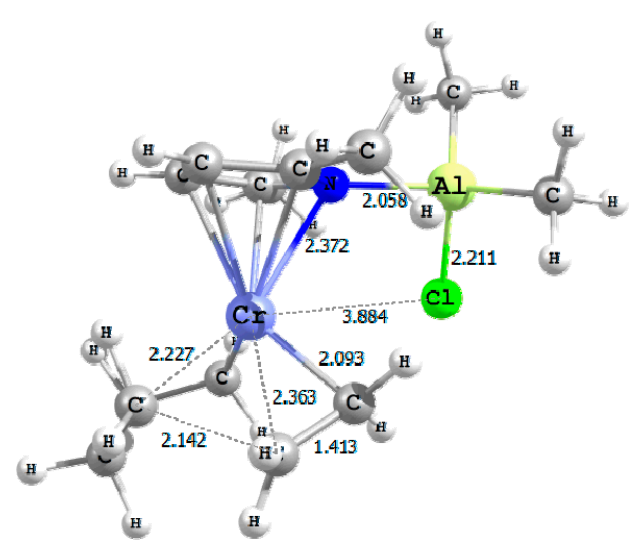

(a)

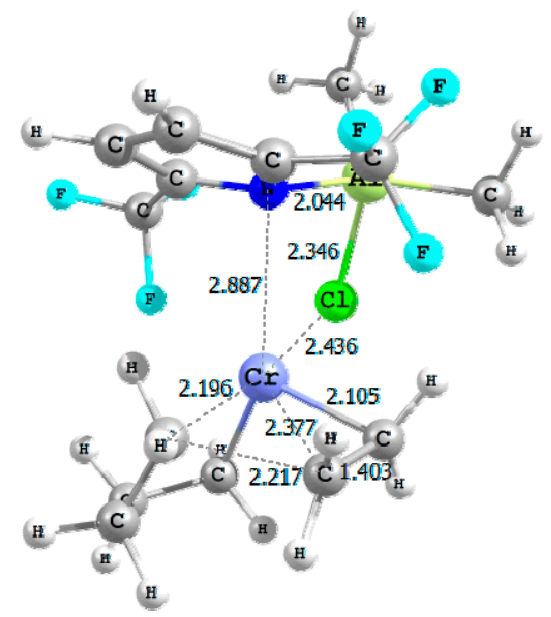

(b)

Figure 3. 3D sketches of TS-4-5 for complexes (a) A and (b) G (selected distances in $\AA$ ).

\subsection{Effect of the Number of $\mathrm{Cl}$ Atoms in $\mathrm{Al}$ Compound}

In the catalyst active center, the $\mathrm{Al}$ compound is represented in the expected active form of $\mathrm{AlEt}_{2} \mathrm{Cl}$, although this $\mathrm{Al}$ based cocatalyst is usually charged to the reactor as the $\mathrm{AlEt}_{3}$ precursor $[6,8]$. It seems that the $\mathrm{Cl}$-Et exchange occurs, during the catalyst activation, between $\mathrm{AlEt}_{3}$ and either the halocarbon promoter or the catalyst precursor. Here, we assumed that at higher halocarbon/catalyst ratios, $\mathrm{AlMeCl}_{2}$ and $\mathrm{AlCl}_{3}$ could also be formed. As a result of such an assumption, the catalytic system can be represented as Scheme 4 .

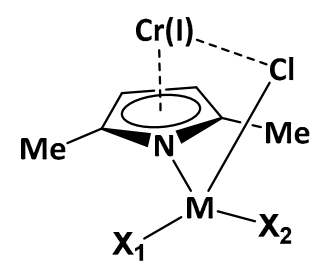

$$
\begin{aligned}
& A: X_{1}=X_{2}=M e ; M=A l \\
& H: X_{1}=C l ; X_{2}=M e ; M=A l \\
& \text { I: } X_{1}=X_{2}=C l ; M=A l \\
& J: X_{1}=X_{2}=M e ; M=B \\
& K: X_{1}=X_{2}=M e ; M=G a
\end{aligned}
$$

Scheme 4. Illustration of model catalysts $(\mathbf{H}-\mathbf{K})$.

In this section, the ethylene oligomerization cycle via these catalysts was explored. Table 3 shows the Gibbs energies of the reaction pathway of ethylene oligomerization catalyzed by the model catalysts $\mathbf{H}$ and $\mathbf{I}$, with respect to $\mathbf{A}$. Since the energy trend in the ethylene oligomerization was nearly the same as that of the studied catalysts (A-E), here, for simplicity, we focus only on the energy barrier of the most probable product (C4, C6, and C8) formations, included in Table 2.

As seen vide supra, the chromocyclopentane 3 could either undergo dimerization, with the release of the 1-butene side product, or face the third ethylene coordination to yield chromocycloheptane, 5. Elimination of the 1-butene side product would cost $26.5,24.7$, and $22.1 \mathrm{kcal} / \mathrm{mol}$ in studied 
catalysts $\mathbf{A}, \mathbf{H}$, and I, respectively, while consecutive coordination of the third ethylene molecule, which leads to 5, needed to overcome a much lower energy barriers of 21.6 and $18.8 \mathrm{kcal} / \mathrm{mol}$ for models $\mathbf{H}$ and I, respectively, to be compared with $24.9 \mathrm{kcal} / \mathrm{mol}$ for A. Further, Liu and coworkers stated that apart from the $\beta-\mathrm{H}$ elimination, the subsequent reduction elimination was even more expensive kinetically [12]. Thus, the energy results here clearly indicated that the third ethylene insertion represented a favorable reaction for all systems, especially for the catalysts with the higher $\mathrm{Cl}$ content i.e., $\mathbf{H}$ and $\mathbf{I}$ model systems.

Table 3. Relative Gibbs free energies in toluene for the models $\mathbf{H}-\mathbf{K}$, with model A for comparison, for the ethylene dimerization, trimerization, and formation of the 7 - and also the 9-membered ring. All energies are in $\mathrm{kcal} / \mathrm{mol}$.

\begin{tabular}{ccccccc}
\hline Model Catalyst & $\mathbf{A}$ & $\mathbf{A}$ & $\mathbf{H}$ & $\mathbf{I}$ & $\mathbf{J}$ & $\mathbf{K}$ \\
\hline Active species & 0.0 & 0.0 & 0.0 & 0.0 & 0.0 & 0.0 \\
$\mathbf{1}$ & -3.0 & -3.4 & -1.9 & -0.6 & 5.2 & -3.1 \\
$\mathbf{2}$ & -1.6 & -2.0 & -2.8 & -3.2 & 16.6 & -0.1 \\
TS-2-3 & 8.4 & 8.0 & 8.2 & 7.2 & 29.1 & 9.9 \\
$\mathbf{3}$ & -9.4 & -10.0 & -7.7 & -6.4 & -1.9 & -9.4 \\
$\mathbf{4}$ & -1.6 & -1.9 & -2.8 & -4.2 & 11.1 & 0.8 \\
TS-4-5 & 15.5 & 15.2 & 13.9 & 12.4 & 26.8 & 14.3 \\
$\mathbf{5}$ & -16.3 & -16.9 & -13.8 & -14.1 & -9.4 & -16.3 \\
TS-5-6 & 4.3 & 3.9 & 2.0 & 1.9 & 13.0 & 6.2 \\
$\mathbf{6}$ & -20.3 & -20.9 & -18.9 & -18.2 & -11.8 & -20.4 \\
$\mathbf{7}$ & -7.2 & -7.6 & -9.6 & -10.2 & 11.3 & -5.7 \\
TS-7-8 & 13.1 & 12.7 & 11.5 & 10.0 & 29.3 & 14.9 \\
$\mathbf{8}$ & -21.0 & -21.6 & -19.4 & -18.8 & -13.7 & -21.2 \\
TS-3-9 & 17.1 & 16.8 & 17.0 & 15.7 & 23.7 & 16.4 \\
$\mathbf{9}$ & -13.3 & -13.8 & -12.2 & -11.1 & -5.8 & -13.3 \\
\hline \multicolumn{7}{c}{ Data in methylcyclohexane. }
\end{tabular}

Similarly, chromocycloheptanes 5 could undergo trimerization with the release of the main product 1-hexene, or the subsequent insertion of an ethylene moiety, to yield chromocyclononane 8 . 1-hexene could be released from 5 throughout direct reductive elimination, with energy barriers of 15.8 and $16.0 \mathrm{kcal} / \mathrm{mol}$ (TS-5-6) for models $\mathbf{H}$ and $\mathbf{I}$, respectively; thus, again the addition of chlorides on the aluminium center facilitates the reaction, since for $\mathbf{A}$ this barrier is $20.6 \mathrm{kcal} / \mathrm{mol}$. Through coordination and subsequent insertion of an ethylene molecule to 5, complex 8 was formed with energy barriers of 29.4, 25.3, and $24.1 \mathrm{kcal} / \mathrm{mol}$ (TS-7-8) in models A, $\mathbf{H}$ and I, respectively. According to our theoretical results, the 1-hexene formation is more favorable for catalysts $\mathbf{H}$ and $\mathbf{I}$ with high chloride levels, so that the fourth ethylene coordination anticipates 1-hexene release, due to its lower barrier.

Concluding this remark, according to Table 3, by increasing the number of chlorides substituted with the methyl group in the composition of the Al-compound, which indicates an increase in the halocarbon/chromium molar ratio, the trimerization must overcome lower energy barriers [14]. In other words, an increase in halocarbons leads to an increase in 1-hexene selectivity [22]. It verifies higher catalyst activity towards 1-hexene formation at higher halocarbon amounts; this result had already been obtained experimentally by Liu et al., with the best performance using 1,1,2,2-tetrachloroethane (TCE) [23].

\subsection{Effect of Metal Type in the Cocatalyst Structure}

As mentioned, the presence of an Al-compound provided by a cocatalyst is indispensable for configuration of the Chevron-Phillips active center of Scheme 1. In this section, the effect of the metal-type in the Al-compound, along the ethylene oligomerization reaction, was investigated. In this regard, Al was substituted by two other group III elements, boron (B) and gallium (Ga), which are considered as a metalloid and a metal, respectively. This produces the two new active catalysts models 
$\mathbf{J}$ and $\mathbf{K}$, respectively (data included in Tables 2 and 3). It is worthy of note that generation of $\mathbf{1}$ from the active catalyst is endergonic for system $\mathrm{J}$, by $5.2 \mathrm{kcal} / \mathrm{mol}$, because of the slightly higher stability of the sextet ground multiplicity state of the latter species.

In quantitatively comparing the catalyst selectivity toward the 1-butene formation with the third ethylene coordination to form 5 , the data clearly showed that the progress of the reaction, i.e., third ethylene coordination, was more energetically efficient for catalyst $\mathbf{A}(20.6 \mathrm{kcal} / \mathrm{mol})$, than $\mathbf{J}$ and $\mathbf{K}$, which showed higher energy barriers $(1.8$ and $3.1 \mathrm{kcal} / \mathrm{mol}$, respectively). Compare these values with the competitive fourth ethylene coordination that leads to the extension of the metallacycle size, with larger energy barriers of 16.3 and $8.7 \mathrm{kcal} / \mathrm{mol}$ for catalysts $\mathbf{J}$ and $\mathbf{K}$, respectively. However, for boron, the catalyst would be selective towards 1-butene, rather than 1-hexene, by $3.1 \mathrm{kcal} / \mathrm{mol}$, due to the electron deficiency. Furthermore, among the catalytically active species, the boron cocatalyst imposes structural differences with respect to the other two studied types of cocatalysts; thus, at this point, we must consider that boron behaves differently to aluminium or gallium. From an energetic point of view, 1-hexene selectivity increases in the following order: $\mathrm{Ga}>\mathrm{Al}$. Concluding this section, calculations suggest a new structure, aluminium based model I, containing relatively electron-withdrawing groups like chlorides, as the catalyst with the highest activity (upper barrier placed at $18.8 \mathrm{kcal} / \mathrm{mol}$ ) and selectivity.

\subsection{Effect of Solvent}

Typically, ethylene oligomerization is conducted in a solvent media at both industrial and laboratory scales, using the Chevron-Phillips catalytic system. Typical oligomerization solvents employed in both academic laboratories and industrial settings are either toluene or some saturated alkanes, such as methylcyclohexane [24-26]. For this reason, the effect on the catalytic cycle of the two most widely used solvents, methylcyclohexane and toluene, was studied.

According to the obtained results (compiled for model A catalyst in Table 3), the inclusion of asolvent effects did not change the trend, and quantitatively the difference between both types of solvents was far less than $1 \mathrm{kcal} / \mathrm{mol}$ in most of cases. Since many authors reported less productivity of trimerization systems in aromatic solvents such as toluene, this indicates that toluene molecules compete with the ligand for coordination to the chromium center to form/stabilize non-selective species. Here the coordination of toluene to species $\mathbf{1}$ becomes competitive, even though it does not change the multiplicity with respect to 1 . The equilibrium is displaced towards toluene by $0.5,2.7$ and $0.4 \mathrm{kcal} / \mathrm{mol}$, for models $\mathrm{A}-\mathrm{C}$, respectively.

\section{Conclusions}

It is shown here that besides ligand and cocatalyst type, even fine details such as halocarbon amount and solvent have a significant effect on productivity and chemoselectivity. Predictive catalysis suggests a modification on the Chevron-Phillips catalyst system to reach higher selectivity and activity, leading to the production of 1-hexene. The increase of the steric hindrance on the pyrrole ring improves the catalytic performance (model $\mathbf{D}$ ). The addition of electron-withdrawing groups (models $\mathbf{F}$ and $\mathbf{G}$ ) should also improve catalysis, but when this effect is too exaggerated (model G), it would lead to decomposition by means of the decoordination of the five-membered ring ligand from the chromium centers. Thus, less electron-withdrawing halides like chloride improve catalytic performance (model I), whereas the rather costly gallium is slightly better (model $\mathbf{K}$ ) than aluminum as a metal. Future experiments should demonstrate whether the catalysts used here as computational models present the features described here, both from a positive and a negative point of view.

\section{Computational Details}

To simulate the Chevron-Phillips catalytic system, a molecular model proposed by Liu et al. [12] (Scheme 1) was used. All DFT calculations were performed using the Gaussian 09 set of programs [27]. In these calculations, the B3LYP, hybrid GGA functional of Becke-Lee, Parr, and Yang [28] was 
employed, since, as reported before, the simulation of transition metals containing systems hybrid functionals give the best performance [29-31]. The electronic configuration of the studied molecules was described with the standard split valence basis set with a polarization function for $\mathrm{H}, \mathrm{C}, \mathrm{Cl}$, $\mathrm{Al}$ and N (SVP keyword in Gaussian) of Ahlrichs and co-workers [32]. The quasi-relativistic, small-core effective core potential of Stuttgart/Dresden, with an associated valence basis set (SDD keyword in Gaussian), was used for the Cr atom [33].

Apart from $\mathrm{Cr}^{\mathrm{III}}$ and $\mathrm{Cr}^{\mathrm{I}}$, unpaired electrons exist for other $\mathrm{Cr}$ based complexes. Due to the tendency of $\mathrm{Cr}$ to exhibit high spin states, the spin multiplicity was studied thoroughly, and the sextet was found to be the ground state multiplicity for the active catalyst, whereas quadruplet for all the other studied complexes, including ethylene coordination, metallacycle and product formation, and the corresponding transition state, even though the sextet is around only $1 \mathrm{kcal} / \mathrm{mol}$ above in energy once bonded an ethylene molecule on the metal (see Table S1). Spin contamination was checked, and was found to be insignificant (see Table S2) [34,35].

Solvent effects on the potential energy surfaces of oligomerization cycle were estimated based on the polarizable continuum solvation model (PCM), using methylcyclohexane and toluene as the solvents [36,37], and triple- $\zeta$ basis set (cc-pVTZ keyword in Gaussian) [38], again B3LYP, together with the Grimme D3BJ correction term to the electronic energy [39]. Thus, the free energies discussed throughout the manuscript include the electronic energies in solvent are corrected by the thermal corrections calculated in gas phase at $\mathrm{T}=298.15 \mathrm{~K}$ and $\mathrm{P}=1 \mathrm{~atm}$.

To determine the steric hindrance around the metal $[16,40]$, topographical steric maps of $\mathrm{NCH}$ ligands were obtained by SambVca 2.0 [41,42], developed by Cavallo et al. The radius of the sphere around the metal center was set to $3.5 \AA$, whereas for the atoms we adopted the Bondi radii scaled by 1.17 , and a mesh of $0.1 \AA$ was used to scan the sphere for buried voxels [43,44].

Supplementary Materials: The following are available online at http:/ /www.mdpi.com/2073-4344/8/6/224/s1, Table S1: Coordinate data sets and absolute energies (in a.u.) of all optimized complexes. Table S2: Spin contamination (in e).

Author Contributions: E.N.-R., M.N.-H., R.J., M.G., A.P., and N.B.-L. have run calculations and contributed to write the manuscript.

Funding: This research was funded by Spanish MINECO for a project CTQ2014-59832-JIN, and EU for a FEDER fund (UNGI08-4E-003).

Acknowledgments: N.B.-L. thanks MOLNAC (www.molnac.unisa.it) for its computer facilities and Iran Polymer and Petrochemical Institute (IPPI) for the granting of the project.

Conflicts of Interest: The authors declare no conflict of interest.

\section{References}

1. Bazvand, R.; Bahri-Laleh, N.; Nekoomanesh-Haghighi, M.; Abedini, H. Highly efficient $\mathrm{FeCl}_{3}$ doped $\mathrm{Mg}(\mathrm{OEt})_{2} / \mathrm{TiCl}_{4}$-based Ziegler-Natta catalysts for ethylene polymerization. Des. Monomers Polym. 2015, 18, 599-610. [CrossRef]

2. Alferov, K.A.; Babenko, I.A.; Belov, G.P. New catalytic systems on the basis of chromium compounds for selective synthesis of 1-hexene and 1-octene. Petrol. Chem. 2017, 57, 1-30. [CrossRef]

3. Haghverdi, M.; Tadjarodi, A.; Bahri-laleh, N.; Nekoomanesh Haghighi, M. Synthesis and characterization of $\mathrm{Ni}(\mathrm{II})$ complexes bearing of 2-(1H-benzimidazol-2-yl)-phenol derivatives as highly active catalysts for ethylene oligomerization. Appl. Organomet. Chem. 2018, 32, e4015. [CrossRef]

4. Haghverdi, M.; Tadjarodi, A.; Bahri-laleh, N.; Nekoomanesh Haghighi, M. Cobalt complexes based on 2-(1H-benzimidazol-2-yl)-phenol derivatives: Preparation, spectral studies, DFT calculations and catalytic behavior toward ethylene oligomerization. J. Coord. Chem. 2017, 70, 1800-1814. [CrossRef]

5. Agapie, T. Selective ethylene oligomerization: Recent advances in chromium catalysis and mechanistic investigations. Chem. Rev. 2011, 255, 861-880. [CrossRef]

6. Alferov, K.A.; Belov, G.P.; Meng, Y. Chromium catalysts for selective ethylene oligomerization to 1-hexene and 1-octene: Recent results. Appl. Catal. A Gen. 2017, 542, 71-124. [CrossRef] 
7. Dixon, J.T.; Green, M.J.; Hess, F.M.; Morgan, D.H. Advances in selective ethylene trimerisation-A critical overview. J. Organomet. Chem. 2004, 689, 3641-3668. [CrossRef]

8. Bahri-Laleh, N.; Karimi, M.; Kalantari, Z.; Fallah, M.; Hanifpour, A.; Nekoomanesh-Haghighi, M. H2 effect in Chevron-Phillips ethylene trimerization catalytic system: An experimental and theoretical investigation. Polym. Bull. 2017. [CrossRef]

9. Makhaev, V.D.; Petrova, L.A.; Alferov, K.A.; Belov, G.P. A Failed Late-Stage Epimerization Thwarts an Approach to Ineleganolide. Russ. J. Org. Chem. 2013, 86, 1819-1824.

10. Jiang, T.; Ji, R.; Chen, H.; Cao, C.; Mao, G.; Ning, Y. Effect of Alkylaluminum Activators on Ethylene Trimerization Based on 2,5-DMP/Cr(III)/TCE Catalyst System. Chin. J. Chem. 2011, 29, 1149-1153. [CrossRef]

11. Gong, M.; Liu, Z.; Li, Y.; Ma, Y.; Sun, Q.; Zhang, J.; Liu, B. Selective Co-Oligomerization of Ethylene and 1-Hexene by Chromium-PNP Catalysts: A DFT Study. Organometallics 2016, 35, 972-981. [CrossRef]

12. Yang, Y.; Liu, Z.; Cheng, R.; He, X.; Liu, B. Mechanistic DFT Study on Ethylene Trimerization of Chromium Catalysts Supported by a Versatile Pyrrole Ligand System. Organometallics 2014, 33, 2599-2607. [CrossRef]

13. Skobelev, I.Y.; Panchenko, V.N.; Lyakin, O.Y.; Bryliakov, K.P.; Zakharov, V.A.; Talsi, E.P. In Situ EPR Monitoring of Chromium Species Formed during $\mathrm{Cr}$-Pyrrolyl Ethylene Trimerization Catalyst Formation. Organometallics 2010, 29, 2943-2950. [CrossRef]

14. Qi, Y.; Dong, Q.; Zhong, L.; Liu, Z.; Qiu, P.; Cheng, R.; He, X.; Vanderbilt, J.; Liu, B. Role of 1, 2-dimethoxyethane in the transformation from ethylene polymerization to trimerization using chromium tris (2-ethylhexanoate)-based catalyst system: A DFT study. Organometallics 2010, 29, 1588-1602. [CrossRef]

15. Riache, N.; Dery, A.; Callens, E.; Poater, A.; Samantaray, M.; Dey, R.; Hong, J.H.; Lo, K.; Cavallo, L.; Basset, J.M. Silica-supported tungsten carbynes $(=\mathrm{SiO})(\mathrm{x}) \mathrm{W}(\mathrm{CH})(\mathrm{Me})(\mathrm{y})(\mathrm{x}=1, \mathrm{y}=2 ; \mathrm{x}=2, \mathrm{y}=1)$ : New efficient catalysts for alkyne cyclotrimerization. Organometallics 2015, 34, 690-695. [CrossRef]

16. Poater, A.; Cosenza, B.; Correa, A.; Giudice, S.; Ragone, F.; Scarano, V.; Cavallo, L. SambVca: A Web Application for the Calculation of Buried Volumes of N-Heterocyclic Carbene Ligands. Eur. J. Inorg. Chem. 2009, 2009, 1759-1766. [CrossRef]

17. Tobisch, S.; Ziegler, T. Catalytic Oligomerization of Ethylene to Higher Linear $\alpha$-Olefins Promoted by the Cationic Group 4 [( $\eta^{5}-\mathrm{Cp}-\left(\mathrm{CMe}_{2}\right.$-bridge $\left.)-\mathrm{Ph}\right) \mathrm{M}^{\mathrm{II}}$ (ethylene $\left.)_{2}\right]^{+}(\mathrm{M}=\mathrm{Ti}, \mathrm{Zr}, \mathrm{Hf})$ Active Catalysts: A Density Functional Investigation of the Influence of the Metal on the Catalytic Activity and Selectivity. J. Am. Chem. Soc. 2004, 126, 9059-9071. [PubMed]

18. Briggs, J.R. The selective trimerization of ethylene to hex-1-ene. J. Chem. Soc. Chem. Commun. 1989, 674-675. [CrossRef]

19. Manzini, S.; Urbina-Blanco, C.A.; Nelson, D.J.; Poater, A.; Lebl, T.; Meiries, S.; Slawin, A.M.Z.; Falivene, L.; Cavallo, L.; Nolan, S.P. Evaluation of an olefin metathesis pre-catalyst with a bulky and electron-rich N-heterocyclic carbene. J. Organomet. Chem. 2015, 780, 43-48. [CrossRef]

20. Licciulli, S.; Albahily, K.; Fomitcheva, V.; Korobkov, I.; Gambarotta, S.; Duchateau, R. A Chromium Ethylidene Complex as a Potent Catalyst for Selective Ethylene Trimerization. Angew. Chem. Int. Ed. 2011, 50, 2346-2349. [CrossRef] [PubMed]

21. Araki, Y.; Nakamura, H.; Nanba, Y.; Okano, T. Process for Producing $\alpha$-Olefin Oligomer. U.S. Patent 5856612A, 5 January 1999.

22. Khasbiullin, I.I.; Belov, G.P.; Kharlampidi, K.E.; Vil'ms, A.I. Ethylene oligomerization on the chromium ethylhexanoate-triethylaluminum-2,5-dimethylpyrrol catalytic system in the presence of carbon tetrachloride. Petrol. Chem. 2011, 51, 450-455. [CrossRef]

23. Tang, S.; Liu, Z.; Yan, X.; Li, N.; Cheng, R.; He, X.; Liu, B. Kinetic studies on the pyrrole-Cr-based Chevron-Phillips ethylene trimerization catalyst system. Appl. Catal. A Gen. 2014, 481, 39-48. [CrossRef]

24. Jabri, A.; Mason, C.B.; Sim, Y.; Gambarotta, S.; Burchell, T.J.; Duchateau, R. Isolation of Single-Component Trimerization and Polymerization Chromium Catalysts: The Role of the Metal Oxidation. State. Angew. Chem. Int. Ed. 2008, 47, 9717-9721. [CrossRef] [PubMed]

25. Jeon, J.Y.; Park, D.S.; Lee, D.H.; Eo, S.C.; Park, S.Y.; Jeong, M.S.; Kang, Y.Y.; Lee, J.; Lee, B.Y. A chromium precursor for the Phillips ethylene trimerization catalyst: (2-ethylhexanoate) ${ }_{2} \mathrm{CrOH}$. Dalton Trans. 2015, 44, 11004-11012. [CrossRef] [PubMed]

26. Zilbershtein, T.M.; Kardash, V.A.; Suvorova, V.V.; Golovko, A.K. Decene formation in ethylene trimerization reaction catalyzed by Cr-pyrrole system. Appl. Catal. A Gen. 2014, 475, 371-378. [CrossRef] 
27. Frisch, M.J.; Trucks, G.W.; Schlegel, H.B.; Scuseria, G.E.; Robb, M.A.; Cheeseman, J.R.; Scalmani, G.; Barone, V.; Mennucci, B.; Petersson, G.A.; et al. Gaussian 09, Revision E.01; Gaussian, Inc.: Wallingford CT, USA, 2009.

28. Becke, A. Density-functional exchange-energy approximation with correct asymptotic behaviour. Phys. Rev. A 1988, 38, 3098-3100. [CrossRef]

29. Bahri-Laleh, N.; Nekoomanesh-Haghighi, M.; Mirmohammadi, S.A. A DFT study on the effect of hydrogen in ethylene and propylene polymerization using a Ti-based heterogeneous Ziegler-Natta catalyst. J. Organomet. Chem. 2012, 719, 74-79. [CrossRef]

30. Bahri-Laleh, N.; Poater, A.; Cavallo, L.; Mirmohammadi, S.A. Exploring the Mechanism of Grignard Methathesis Polymerization of 3-alkylthiophenes. Dalton Trans. 2014, 43, 15143-15150. [CrossRef] [PubMed]

31. Correa, A.; Bahri-Laleh, N.; Cavallo, L. How well can DFT reproduce key interactions in Ziegler-Natta systems? Macromol. Chem. Phys. 2013, 214, 1980-1989. [CrossRef]

32. Schäfer, S.; Horn, H.; Ahlrichs, R. Fully Optimized Contracted Gaussian Basis Sets for Atoms Li to Kr. J. Chem. Phys. 1992, 97, 2571-2577. [CrossRef]

33. Küchle, W.; Dolg, M.; Stoll, H.; Preuss, H. Energy-Adjusted Pseudopotentials for the Actinides. Parameter Sets and Test Calculations for Thorium and Thorium Monoxide. J. Chem. Phys. 1994, 100, 7535-7542. [CrossRef]

34. Costas, M.; Ribas, X.; Poater, A.; López Balvuena, J.M.; Xifra, R.; Company, A.; Duran, M.; Solà, M.; Llobet, A.; Corbella, M.; et al. Copper(II) Hexaaza Macrocyclic Binuclear Complexes Obtained from the Reaction of Their Copper(I) Derivates and Molecular Dioxygen. Inorg. Chem. 2006, 45, 3569-3581. [CrossRef] [PubMed]

35. Poater, A.; Ribas, X.; Llobet, A.; Cavallo, L.; Solà, M. Complete Mechanism of $\sigma^{*}$ Intramolecular Aromatic Hydroxylation through $\mathrm{O}_{2}$ Activation by a Macrocyclic Dicopper(I) Complex. J. Am. Chem. Soc. 2008, 130, 17710-17717. [CrossRef] [PubMed]

36. Barone, V.; Cossi, M. Quantum Calculation of Molecular Energies and Energy Gradients in Solution by a Conductor Solvent Model. J. Chem. Phys. A 1998, 102, 1995-2001. [CrossRef]

37. Tomasi, J.; Persico, M. Molecular Interactions in Solution: An Overview of Methods Based on Continuous Distributions of the Solvent. Chem. Rev. 1994, 94, 2027-2094. [CrossRef]

38. Kendall, R.A.; Dunning, T.H., Jr.; Harrison, R.J. Electron affinities of the first-row atoms revisited. Systematic basis sets and wave functions. J. Chem. Phys. 1992, 96, 6796-6806. [CrossRef]

39. Grimme, S.; Antony, J.; Ehrlich, S.; Krieg, H. A Consistent and Accurate Ab Initio Parametrization of Density Functional Dispersion Correction (DFT-D) for the 94 Elements H-Pu. J. Chem. Phys. 2010, 132, 154104. [CrossRef] [PubMed]

40. Jacobsen, H.; Correa, C.; Poater, A.; Costabile, C.; Cavallo, L. Understanding the M-(NHC) (NHC = N-Heterocyclic Carbene) Bond. Coord. Chem. Rev. 2009, 253, 687-703. [CrossRef]

41. Falivene, L.; Credendino, R.; Poater, A.; Petta, A.; Serra, L.; Oliva, R.; Scarano, V.; Cavallo, L. SambVca 2. A Web Tool for Analyzing Catalytic Pockets with Topographic Steric Maps. Organometallics 2016, 35, 2286-2293. [CrossRef]

42. Poater, A.; Cavallo, L. Comparing families of olefin polymerization precatalysts using the percentage of buried volume. Dalton Trans. 2009, 2009, 8878-8883. [CrossRef] [PubMed]

43. Poater, A.; Falivene, L.; Urbina-Blanco, C.A.; Manzini, S.; Nolan, S.P.; Cavallo, L. How does the Addition of Steric Hindrance to a Typical N-heterocyclic Carbene Ligand Affect Catalytic Activity in Olefin Metathesis? Dalton Trans. 2013, 42, 7433-7439. [CrossRef] [PubMed]

44. Poater, A.; Ragone, F.; Giudice, S.; Costabile, C.; Dorta, R.; Nolan, S.P.; Cavallo, L. Thermodynamics of N-heterocyclic carbene dimerization: The balance of sterics and electronics. Organometallics 2008, 27, 2679-2681. [CrossRef]

(C) 2018 by the authors. Licensee MDPI, Basel, Switzerland. This article is an open access article distributed under the terms and conditions of the Creative Commons Attribution (CC BY) license (http:/ / creativecommons.org/licenses/by/4.0/). 